\title{
Specific flavonoids as interconnecting signals in the tripartite symbiosis formed by arbuscular mycorrhizal fungi, Bradyrhizobium japonicum (Kirchner) Jordan and soybean (Glycine max (L.) Merr.)
}

\author{
Pedro M. Antunes*, Istvan Rajcan, Michael J. Goss \\ Department of Land Resource Science, University of Guelph, Richards Building, Guelph, Ont., Canada N1G 2W1
}

Received 20 February 2005; received in revised form 8 June 2005; accepted 12 June 2005

Available online 19 July 2005

\begin{abstract}
Many legume plants benefit from the tripartite symbiosis of arbuscular mycorrhizal fungi (AMF) and rhizobia. Beneficial effects for the plant have been assumed to rely on increased P supply through the mycorrhizas. Recently, we demonstrated that P does not regulate the establishment of the tripartite symbiosis. Flavonoids appear to play a role as early signals for both rhizobia and AMF. Four soybean lines known to express different concentrations of the isoflavones genistein, daidzein and glycitein in the seed were used to test three hypotheses: (i) The establishment of the tripartite symbiosis is not dependent of a nutrient mediated effect; (ii) There is a positive correlation between seed isoflavone concentrations of different soybean lines and the progress of the tripartite symbiosis; (iii) Specific flavonoids control the establishment of the tripartite symbiosis in that a change in flavonoid root accumulation resulting from the development of one microbial partner can stimulate colonization of soybean roots by the other. Disturbed versus undisturbed soil treatments were produced to vary the potential for indigenous AMF colonization of soybean. In contrast, the potential for Bradyrhizobium was kept identical in both soil disturbance treatments. The uptake of $\mathrm{P}$ and $\mathrm{Zn}$ and the concentration of flavonoids in mycorrhizal soybean roots at $10 \mathrm{~d}$ after emergence were analysed either separately of Bradyrhizobium or in context of the tripartite symbiosis. Zinc nutrition did not differ between AMF treatments which supports the first hypothesis. The concentration of daidzein was at least four times greater in the root than in the seed

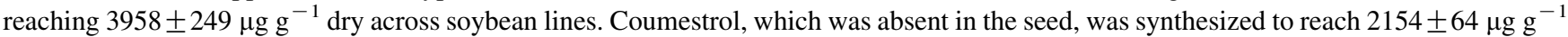
dry. Conversely, the concentration of genistein was approximately three times smaller in the root that in the seed ( $301 \pm 15 \mu \mathrm{g} \mathrm{g}^{-1} \mathrm{dry}$, while glycitein and formononetin were never detected. The establishment of the tripartite symbiosis was identical across soybean lines which does not support the second hypothesis. Concentrations of flavonoids were significantly greater in roots under disturbed soil, for which both symbioses were not as developed as in plants from undisturbed soil. This clearly supports the third hypothesis. This research provides the first data linking the function of different flavonoids to the establishment of the tripartite symbiosis, and suggests that these compounds are produced and released into the rhizosphere as a function of the colonization process.
\end{abstract}

(C) 2005 Elsevier Ltd. All rights reserved.

Keywords: Tripartite symbiosis; Signalling; Flavonoids; Arbuscular mycorrhizal fungi; Rhizobia; Soybean; Early interaction; Legume

\section{Introduction}

Soybean (Glycine max (L.) Merr.) forms associations with arbuscular mycorrhizal fungi (AMF) and Bradyrhizobium japonicum (Kirchner) Jordan. The presence of one microbial symbiont has been shown to affect the activity of the other and the interaction of both microbial symbionts

\footnotetext{
* Corresponding author. Tel.: +1 519 8244120; fax: +1 5197671656

E-mail address: pantunes@uoguelph.ca (P.M. Antunes).
}

0038-0717/\$ - see front matter (C) 2005 Elsevier Ltd. All rights reserved. doi:10.1016/j.soilbio.2005.06.008 can be detected on the host plant (e.g., Cluett and Boucher, 1983; Barea et al., 1992; Vejsadová et al., 1993; Xie et al., 1995). This interaction among the three organisms results in a mutualistic tripartite symbiosis (El-Hassanin and Lynd, 1985). Generally, under laboratory conditions, $\mathrm{N}_{2}$-fixation in mycorrhizal soybeans is greater than in non-mycorrhizal plants, with more nodules having a greater total dry weight (Goss and de Varennes, 2002). Significantly, the effect on nodule number and weight can be detected as early as $10 \mathrm{~d}$ after emergence either under laboratory or field conditions and this has the potential to boost $\mathrm{N}_{2}$ fixation at later periods of plant growth (P.M. Antunes, 2004, Ph.D. thesis, University of Guelph, Canada). Although it has been 
assumed that the beneficial effects of the tripartite symbiosis on $\mathrm{N}_{2}$-fixation rely completely on increased supply of phosphorus to the plant by the symbiotic fungal partner (e.g., Vejsadová et al., 1993; George et al., 1995), this mechanism is not operating during the early stages of plant development, when the increase in nodulation can already be detected (P.M. Antunes, 2004, Ph.D. thesis, University of Guelph, Canada). Nevertheless, there are no data available to indicate what role other nutrients commonly supplied through mycorrhizal hyphae (e.g., zinc) may play in the establishment of the tripartite symbiosis, and the likelihood of a micronutrient-mediated effect is assessed in this research.

Several common steps are involved in the establishment of these symbioses (Antunes and Goss, in press). Given that the hypothesis of a P-mediated effect was rejected, alternatively, signalling appears to be a more likely mechanism by which the tripartite symbiosis is regulated in its early stages. Flavonoids such as coumestrol and daidzein have been shown to stimulate AMF colonization in a variety of plants (see review by Vierheilig et al., 1998), and their synthesis appears to increase in the presence of the fungi even before root colonization (Larose et al., 2002). Even though various changes in the pattern of flavonoid accumulation have been reported (e.g., Morandi et al., 1984; Harrison and Dixon, 1993; Larose et al., 2002), the information in the literature is inconsistent. Bécard et al. (1995) suggested that flavonoids are not essential as stimulatory compounds for AMF. This may, however, simply imply that only some flavonoids have an effect on $\mathrm{AMF}$ and the host plant may determine those that are required.

Daidzein, genistein and coumestrol are primary flavonoids in soybean which induce the transcription of nodulation genes in B. japonicum (e.g., Kosslak et al., 1987; Peters and Verma, 1990; Rao and Cooper, 1995; Zhang and Smith, 1995). Most of these genes regulate the synthesis of specific Nod factors (Fisher and Long, 1993), which stimulate the synthesis and exudation of flavonoids by the roots (Schmidt et al., 1994; Xie et al., 1995). Very little is known about glycitein and formononetin. The latter, for example, accumulates in the vacuoles of the nodule progenitor cells (Mathesius et al., 1998), and appears to act as a plant mediator in the control of AMF colonization (Larose et al., 2002).

There are abundant data on the effect of individual compounds in vitro, usually presented for a single type of symbiosis. However, no reports that focus on assessing the role of individual flavonoids in the context of the tripartite symbiosis of Bradyrhizobium, indigenous AMF and soybean were found in the literature. Many of the experimental observations have improved the understanding on the details involved in the system, but were produced in highly artificial conditions not necessarily comparable to the complexity of the rhizosphere of a real soil-plant environment. Studies using experimental conditions that involve the whole plant-soil system both in space and time are pivotal to clarify the importance and precise role of flavonoids in the mycorrhizal-rhizobial interaction and this is a key objective of this work.

In this investigation three main hypotheses are tested: (i) The establishment of the tripartite symbiosis, which is characterized by improved AMF colonization and nodulation, is not dependent of a nutrient mediated effect; (ii) There is a positive correlation between seed isoflavone concentrations of different soybean lines and the early progress of the tripartite symbiosis; (iii) Specific flavonoids control the establishment of the tripartite symbiosis in that a change in flavonoid root accumulation resulting from the development of one microbial partner can stimulate colonization of soybean roots by the other.

\section{Materials and methods}

The experiment consisted of a preliminary phase, in which maize was grown over periods of 3 weeks. There were four cycles of maize growth to promote the development of indigenous AMF within the soil, with three of these to establish a differential mycorrhizal inoculum potential (Goss and de Varennes, 2002), followed by the investigation of inter-organism communication between soybean, mycorrhizal fungi and Bradyrhizobium focusing on an early stage of plant development (first trifoliolate).

\subsection{Soil and growing conditions}

The experiment was conducted under controlled environment conditions in a growth-room. The growth-room was set to a $16 \mathrm{~h} \mathrm{~d}^{-1}$ at $25^{\circ} \mathrm{C}$ with a light intensity of $250 \mu \mathrm{mol} \mathrm{s}{ }^{-1} \mathrm{~m}^{-2}$, and $8 \mathrm{~h}$ night at $18^{\circ} \mathrm{C}$. To maximize the visible light spectrum, a combination of three different types of $215 \mathrm{~W}$ fluorescent lamps (Sylvania Cool White F96T12/CW/VHO, Industrial F96T12/GL/WS/VHO and Vitalux Duro-Test F96T-12) and regular $40 \mathrm{~W}$ incandescent lamps were used. Infestation by thrips, mites and fungus gnats was prevented by using their respective mite predators Amblyseius cucumeris, Phytoseiulus persimilis and Hypoaspis miles. These biological control agents were applied to the leaves as larvae in a sawdust medium.

Soil, a fine sandy loam, was collected on 23 September 2002 , from the top $20 \mathrm{~cm}$ of an arable field on a farm near Belwood $\left(43^{\circ} 45^{\prime} \mathrm{N} 80^{\circ} 15^{\prime} \mathrm{W}\right)$, Ontario, Canada.

The soil was broken up mechanically and passed through a $4 \mathrm{~mm}$ sieve before use. The soil was packed into 31 pots to a bulk density of approximately $1.3 \mathrm{~g} \mathrm{~cm}^{-3}$. It was assessed for $2.0 \mathrm{M} \mathrm{KCl}$-extractable $\mathrm{NH}_{4}-\mathrm{N}$ and $\mathrm{NO}_{3}-\mathrm{N}$ in a colorimeter Technicon TRAACS 800 (Technical Random Access Automated Chemistry System) (Keeney and Nelson, 1982), $0.5 \mathrm{M} \mathrm{NaHCO}$-extractable $\mathrm{P}$ in a colorimeter Technicon Auto Analyzer II (Olsen and Summers, 1982), 
1.0 M neutral ammonium-acetate extractable $\mathrm{K}$ and $\mathrm{Mg}$ by flame atomic absorption spectrometry (F-AAS; model Varian SpectrAA-300) (Knudsen et al., 1982) and pH (1:1 in water). It was believed that soybeans had never been grown in the soil. Soybeans were sown in pots of the soil and they failed to nodulate by the time of full bloom, confirming the absence of Bradyrhizobium.

\subsection{Preliminary phase}

Maize seeds (Zea mays L. cv. Pioneer 3905) were surface-sterilized (95\% alcohol for $1 \mathrm{~min}$ ), rinsed thoroughly with deionised water, and then germinated in moist sterilized (autoclaved at $121^{\circ} \mathrm{C}$ for $15 \mathrm{~min}$ ) vermiculite. Three days later, on 1 October 2002, three seedlings were planted into each of 51 pots $(3 \mathrm{l})$ containing the equivalent of $3050 \mathrm{~g}$ of oven-dried soil. The gravimetric water content of the soil was adjusted to approximately $200 \mathrm{mg} \mathrm{H}_{2} \mathrm{O} \mathrm{g}^{-1}$ dry soil, and then maintained at that concentration by irrigating with deionised water every second day. The pots were completely randomized before each irrigation. Once the seedlings emerged and produced the coleoptile leaf, they were thinned to two plants per pot. On 21 October 2002, 3 weeks after emergence, all shoots were excised, measured, dried at $65^{\circ} \mathrm{C}$ for $48 \mathrm{~h}$, and weighed. The shoot material was ground in a Wiley mill model 3 (Thomas Scientific, Swedsboro, NJ), digested in sulphuric acid-hydrogen peroxide and analysed for nitrogen (N) and phosphorus (P) using colorimetric methods (Thomas et al., 1967). Twenty four pots were taken, the soil removed and passed through a $4 \mathrm{~mm}$ sieve. All root material separated on the sieve was cut into $2 \mathrm{~cm}$ long segments and mixed into the soil. The soil was repacked in the pots to a density of $1.3 \mathrm{~g} \mathrm{~cm}^{-3}$ and arranged in the same continuous profile. On 23 October 2002, three more surfacesterilized and pre-germinated maize seeds were added to each of the 51 pots; 24 with the soil that had been re-sieved and 27 with soil that was left undisturbed. Plants were thinned to two per pot shortly after emergence, and excised 3 weeks after emergence. The height and dry weight of the shoots were determined, and the plant material from pots of each soil disturbance treatment prepared for analysis of $\mathrm{N}$ and $\mathrm{P}$ as described earlier.

Two more 3-week cycles of maize starting 14 November 2002, and 11 December 2002, respectively, were carried out, with 24 pots containing soil that was sieved before planting, and 27 containing soil that was always left undisturbed. After 3 weeks of growth maize may take up from soil as much as $43 \mathrm{mg} \mathrm{N}$ plant $^{-1}$ (Goss and de Varennes, 2002). Given the small soil mineral N concentrations determined prior to use (see Table 1), $\mathrm{N}$ fertilizer, as an aqueous solution of ammonium-nitrate, was applied in a $50 \mathrm{ml}$ volume to each pot at a rate of $25 \mathrm{mg} \mathrm{N} \mathrm{kg}^{-1}$ dry soil. At the end of the fourth cycle (1 January 2003), soil from pots assigned to the disturbance treatment was re-sieved. During this procedure small portions of soil were randomly
Table 1

Soil concentrations of $\mathrm{NH}_{4}-\mathrm{N}, \mathrm{NO}_{3}-\mathrm{N}, \mathrm{P}, \mathrm{K}, \mathrm{Mg}$ and soil $\mathrm{pH}$ prior to use and after conclusion of the fourth maize cycle (Values in parentheses represent SEM)

\begin{tabular}{llll}
\hline & \multicolumn{2}{l}{ Soil } & \\
\cline { 2 - 4 } & Prior to use & \multicolumn{2}{l}{ After 4th maize cycle } \\
\cline { 3 - 4 } & & Undisturbed & Disturbed \\
\hline $\mathrm{NH}_{4}-\mathrm{N}\left(\mathrm{mg} \mathrm{kg}^{-1}\right)$ & $2.5(0.35) \mathrm{a}$ & $2.6(0.48) \mathrm{a}$ & $5.8(2.13) \mathrm{a}$ \\
$\mathrm{NO}_{3}-\mathrm{N}\left(\mathrm{mg} \mathrm{kg}^{-1}\right)$ & $7.4(0.31) \mathrm{b}$ & $4.1(0.21) \mathrm{c}$ & $21.8(1.59) \mathrm{a}$ \\
$\mathrm{P}\left(\mathrm{mg} \mathrm{kg}^{-1}\right)$ & $28.8(1.97) \mathrm{b}$ & $33.5(1.20) \mathrm{a}$ & $25.6(0.33) \mathrm{b}$ \\
$\mathrm{K}\left(\mathrm{mg} \mathrm{kg}^{-1}\right)$ & $181.5(4.17) \mathrm{a}$ & $67.3(3.18) \mathrm{b}$ & $71.7(1.20) \mathrm{b}$ \\
$\mathrm{Mg}\left(\mathrm{mg} \mathrm{kg}^{-1}\right)$ & $148.8(3.50)$ & $\mathrm{ND}$ & $\mathrm{ND}$ \\
$\mathrm{pH}(1: 1$ in water $)$ & $6.4(0.03) \mathrm{a}$ & $6.5(0.03) \mathrm{a}$ & $6.2(0.03) \mathrm{a}$ \\
\hline
\end{tabular}

Values in a row followed by the same letter are not significantly different $(P<0.05)$. ND—not determined.

taken for nutrient analyses. Three additional pots had been prepared at the onset to assess the concentration of nutrients in undisturbed soil at the end of the fourth maize cycle so that comparisons between disturbance treatments could be made.

\subsection{Inter-organism communication phase}

The second phase of the study consisted of growing in the remaining 48 pots soybean lines known to express different concentrations and arrays of the isoflavones glycitein, genistein and daidzein in the seed (Primomo et al., 2001, data presented at the Soil Science Society of America Annual Meeting in Charlotte, NC). Each pot was treated as an experimental unit. Harovinton is classified as a Canadian food-grade soybean developed by Agriculture and Agri-Food Canada, and is known as 'Asian Pearl' in oriental countries. AC 756 is a registered line of Hyland Seeds (Blenhein, ON) also developed by AAFC, and OAC Arthur and RCAT Angora are registered oilseed lines marketed by SeCan Association (Ottawa, ON) developed by the University of Guelph. The differences in seed isoflavone content among the seed lines make them interesting tools to study plant-microbial symbioses. Generally, Harovinton and RCAT Angora have extremes in isoflavone content of the seed with the former being known to have a relative small content and the latter a large content. AC 756 and OAC Arthur are also known to express relatively larger and smaller isoflavone contents respectively, but are not extreme phenotypes for this factor as in the case of the two other lines.

The experimental layout adopted for the study consisted of a $4 \times 2 \times 2$ factorial experiment involving four soybean lines (Harovinton, OAC Arthur, AC 756 and RCAT Angora), two soil disturbance treatments (undisturbed and disturbed), and two Bradyrhizobium treatments (inoculated and non-inoculated). The treatments were arranged in a completely randomized design with three replications.

Nine soybean seeds of each line were surface-sterilized and germinated in moist sterilized (autoclaved at $121{ }^{\circ} \mathrm{C}$ for 
$15 \mathrm{~min}$ ) vermiculite. Pre-germinated seeds were then planted into each appropriate pot by 9 January 2003 . Inoculation consisted of placing $0.25 \mathrm{~g}$ of peat-based inoculant of B. japonicum strain 532C (MicroBio, Saskatoon, SK, HiStick + ) at the bottom of each small hole into which each soybean seedling was planted. In pots assigned to the non-inoculated treatment, $0.25 \mathrm{~g}$ of sterilized (autoclaved at $121{ }^{\circ} \mathrm{C}$ for $15 \mathrm{~min}$ ) inoculant were also placed at the bottom of each seedling hole so that the soil chemical and physical conditions surrounding the newly formed radicle were kept similar for both treatments. The fact that each radicle passed through the same amount of inoculant in all treatments ensured that the colonization potential for B. japonicum was identical in the two disturbance treatments. Plants were thinned to 6 plants per pot (for statistical purposes, each plant was considered a sub-sample within the experimental unit) $5 \mathrm{~d}$ after planting. Soybean plants were harvested $10 \mathrm{~d}$ after emergence on 23 January 2003. The height and wet weight of the shoots were determined, and these were then freeze dried (Labconco Freeze Dryer 18), weighed dry, and finely ground for $\mathrm{N}$ and $\mathrm{P}$ analysis after sulphuric acid-hydrogen peroxide digestion as described earlier (Thomas et al., 1967). The digests were also analysed for $\mathrm{Zn}$ by Flame Atomic Absorption Spectrometry (F-AAS; model SpectraAA-300) (Richards, 1993). For each pot with Harovinton, OAC Arthur and RCAT Angora lines, which represent low, medium and high seed isoflavone phenotypes respectively, root systems of three plants were carefully washed out of soil, freeze dried, weighed and finely ground with a mortar and pestle for analysis of glycitein, daidzein, genistein, coumestrol and formononetin. The batch of seeds used was also analysed for these same compounds and the results were consistent with those of Primomo et al. (2001, see above). Concentrations of flavonoids were determined using a high-performance liquid chromatography (HPLC) method modified from Franke et al. (1995). Finely ground soybean seed or root were weighed in duplicate samples of $0.5 \mathrm{~g}$ each and dispersed in $10 \mathrm{ml}$ of ethanol plus $2 \mathrm{ml}$ of concentrated $\mathrm{HCl}$. The resulting solutions were hydrolysed by heating to $125^{\circ} \mathrm{C}$ for $2 \mathrm{~h}$ in a sand bath. After cooling, they were centrifuged at $3000 \mathrm{rev} \mathrm{min}^{-1}$ for $10 \mathrm{~min}$ The clear aliquot was filtered through a $0.45 \mu \mathrm{m}$ PTFE filter. HPLC analysis was performed on a Waters 600E equipped with a Waters Nove Pak $\mathrm{C}_{18}$ column $(3.9 \times 150 \mathrm{~mm}, 5 \mu \mathrm{m}$ particle size $)$ and a photodiode array (PDA) detector set to collect spectra from 200 to $300 \mathrm{~nm}$. The flavonoids were separated by a 25 min linear gradient from 30 to $75 \%$ of $100 \%$ methanol in $4 \%$ aq. acetic acid at a flow rate of $1.5 \mathrm{ml} \mathrm{min}^{-1}$ and injection volume of $5 \mu \mathrm{l}$. Recovery was monitored by the addition of a flavone standard to the sample prior to hydrolysis. The compound identification was based on the peak retention times (daidzein, $13.09 \mathrm{~min}$; coumestrol, $15.60 \mathrm{~min}$; glycitein, $16.16 \mathrm{~min}$; formononetin, $16.50 \mathrm{~min}$; genistein; $19.62 \mathrm{~min}$; recovery standard (flavone), $22.89 \mathrm{~min}$ ). and the comparison with the UV spectra of the standards (obtained from Indofine Co, Sommerville, $\mathrm{NJ})$. The remaining three root systems, after being carefully washed out of the soil, were fixed in formyl acetic alcohol, cleared in $\mathrm{KOH}$, and stained with chlorazol-black $\mathrm{E}$ (Brundrett et al., 1984) before being examined for AM colonization by the intersections method described by McGonigle et al. (1990). Four microscope slides were prepared for a representative root sample of each experimental unit, and a minimum of 200 intersections per sample was considered. All root systems were examined for nodules, and those visible with the unaided eye were counted.

\subsection{Statistical analysis}

For data collected during the preliminary phase of maize cycles comparisons between means were made using $t$-tests for independent samples. Data collected in the second phase of the study were examined by analysis of variance (ANOVA) as a completely randomized design (CRD). The Shapiro-Wilk's $W$ test was used to assess if the observations followed a normal distribution (Shapiro et al., 1968). The assumption of homogeneity of variances was confirmed by the Levene's test (Conover et al., 1981). Nonhomogenous data were analysed with the Kruskal-Wallis non-parametric test (Kruskal and Wallis, 1952). This test assesses the data by ranking them; therefore, no assumptions were made.

Unless otherwise specified, when the F-test of the treatment mean square indicated that there were significant variances due to treatment effects, means were compared using the Tukey's HSD (honest significance difference) test $(P<0.05)$ (Tukey, 1949). Tests were performed using the computer software package STATISTICA for the Microsoft Windows operating system (StatSoft, Inc., 1995).

\section{Results}

\subsection{Preliminary phase}

By the end of the fourth maize cycle the concentration of $\mathrm{NO}_{3}-\mathrm{N}$ in disturbed soil was five times greater than in undisturbed soil, reaching $21.8 \mathrm{mg} \mathrm{kg}^{-1}$ (Table 1). Such concentration is equivalent to approximately $42 \mathrm{~kg} \mathrm{~N} \mathrm{ha}^{-1}$ considering a bulk density of $1.3 \mathrm{~g} \mathrm{~cm}^{-3}$ in the top $15 \mathrm{~cm}$.

Maize plants in the last cycle were considered to represent a bioassay of the establishment of any differential mycorrhizal inoculum between the disturbed and undisturbed soil (Table 2). From the second maize cycle onwards, $\mathrm{P}$ uptake by plants grown in undisturbed soil was greater than the uptake by plants from disturbed soil, suggesting a higher potential for AMF colonization in pots where the extra-radical mycorrhizal hyphae were left intact. 
Table 2

Effect of differential soil disturbance (disturbed or undisturbed) on the growth and $\mathrm{N}$ and $\mathrm{P}$ content of maize after each three week cycle (Values in parentheses represent SEM)

\begin{tabular}{lllll}
\hline Cycle and disturbance & Plant height $(\mathrm{cm})$ & ${\text { Shoot weight }\left(\mathrm{g} \mathrm{plant}^{-1}\right)}{\mathrm{N} \text { content }\left(\mathrm{mg} \mathrm{plant}^{-1}\right)}^{\mathrm{P}_{\text {content }}\left(\mathrm{mg} \mathrm{plant}^{-1}\right)}$ \\
\hline Disturbed & $59.6(1.12)$ & $1.3(0.05)$ & $21.4(0.30)$ & $2.6(0.02)$ \\
Disturbed & $52.3(0.47) \mathrm{a}$ & $0.7(0.01) \mathrm{a}$ & $11.6(0.32) \mathrm{a}$ & $1.4(0.02) \mathrm{b}$ \\
Undisturbed & $47.7(0.64) \mathrm{b}$ & $0.5(0.01) \mathrm{b}$ & $9.2(0.10) \mathrm{b}$ & $2.1(0.04) \mathrm{a}$ \\
Disturbed & $60.5(0.51) \mathrm{b}$ & $1.1(0.02) \mathrm{b}$ & $31.1(0.77) \mathrm{a}$ & $2.1(0.04) \mathrm{b}$ \\
Undisturbed & $65.1(0.40) \mathrm{a}$ & $1.4(0.03) \mathrm{a}$ & $23.2(0.29) \mathrm{b}$ & $4.3(0.04) \mathrm{a}$ \\
Disturbed & $53.1(0.57) \mathrm{b}$ & $0.7(0.02) \mathrm{b}$ & $21.1(0.05) \mathrm{a}$ & $1.1(0.01) \mathrm{b}$ \\
Undisturbed & $59.6(0.45) \mathrm{a}$ & $1.0(0.03) \mathrm{a}$ & $18.3(0.24) \mathrm{b}$ & $3.5(0.02) \mathrm{a}$ \\
\hline
\end{tabular}

For each cycle, values in a column followed by the same letter are not significantly different $(P<0.05)$.

Even though the plants grown in disturbed soil had taken up more $\mathrm{N}$ than those grown in undisturbed soil during the third and fourth cycles, the latter were taller and heavier (Table 2). The biomass increase of these plants is another indication of a higher AMF potential in undisturbed soil.

\subsection{Inter-organism communication phase}

\subsubsection{Plant growth and nutrition}

The increase in mass of soybean shoots during the initial $10 \mathrm{~d}$ post-emergence was slower in the undisturbed soil than in the disturbed soil (Table 3). Conversely, no differences in shoot height and shoot:root ratio were observed between soybeans from disturbed and undisturbed soil. There was more $\mathrm{NO}_{3}^{-}-\mathrm{N}$ available in the disturbed soil (Table 2), and plants under this treatment took up approximately $40 \%$ more $\mathrm{N}$ than plants grown in undisturbed soil (Table 3). Moreover, the $\mathrm{P}$ and $\mathrm{Zn}$ contents of the young plants in the first $10 \mathrm{~d}$ after emergence were similar irrespective of the disturbance treatment.

\subsubsection{Root colonization by indigenous AMF and Bradyr- hizobium japonicum}

Soil disturbance significantly affected the potential for AMF colonization (Fig. 1). The colonization of roots by AM fungal hyphae, arbuscules and vesicles was generally four times greater in undisturbed soil than in disturbed soil. Soybeans more heavily colonized by AMF in undisturbed soil had also approximately $30 \%$ more nodules than plants from disturbed soil. There was no difference in the degree of mycotrophy between soybean lines since the development of root colonization by mycorrhizas was very similar in all four lines (Fig. 1). The presence of the bacterial symbiont did not affect root colonization by the fungal symbiont (Fig. 2).

\subsubsection{Accumulation of flavonoids in soybean roots}

The roots of all three soybean lines contained similar concentrations of flavonoids at $10 \mathrm{~d}$ after emergence, although values for daidzein were $25 \%$ greater in RCAT Angora than in Harovinton (Fig. 3). Glycitein and formononetin could not be detected. The concentration of daidzein was at least four times greater in the root than in the seed, and coumestrol, which is not present in the seed, had been accumulated to a concentration in excess of $2000 \mu \mathrm{g} \mathrm{g}^{-1}$. In contrast, the concentration of genistein in the roots was approximately three times smaller than the value found in the seed.

The concentration of daidzein, coumestrol and genistein in roots of all soybean lines from undisturbed soil was

Table 3

Effect of soil disturbance (disturbed or undisturbed) on the growth and N, P and Zn contents of four soybean lines $10 \mathrm{~d}$ after emergence (Values in parentheses represent SEM)

\begin{tabular}{|c|c|c|c|c|c|c|}
\hline $\begin{array}{l}\text { Soybean line Soil } \\
\text { disturbance }\end{array}$ & $\begin{array}{l}\text { Shoot weight } \\
\left(\mathrm{mg} \mathrm{plant}^{-1}\right)\end{array}$ & $\begin{array}{l}\text { Plant height } \\
\left(\mathrm{mm} \mathrm{plant}^{-1}\right)\end{array}$ & $\begin{array}{l}\text { Shoot:root } \\
\text { (weight ratio) }\end{array}$ & $\begin{array}{l}\mathrm{N} \text { content } \\
\left(\mathrm{mg} \text { plant }^{-1}\right)\end{array}$ & $\begin{array}{l}\text { P content } \\
\left(\mathrm{mg} \mathrm{plant}^{-1}\right)\end{array}$ & $\begin{array}{l}\text { Zn content } \\
\left(\mu \text { p plant }^{-1}\right)\end{array}$ \\
\hline \multicolumn{7}{|l|}{ Harovinton } \\
\hline Disturbed & 400 (13) a & $115(3.4) \mathrm{a}$ & $3.4(0.66)$ a & $17.9(0.75) \mathrm{a}$ & $1.0(0.08) \mathrm{a}$ & $2.5(0.63) \mathrm{a}$ \\
\hline $\begin{array}{l}\text { Undisturbed } \\
\text { OAC Arthur }\end{array}$ & $310(10) b$ & $114(2.6) \mathrm{a}$ & $2.9(0.37) \mathrm{a}$ & $13.3(0.47) \mathrm{b}$ & $1.3(0.03) \mathrm{a}$ & $3.4(0.36) \mathrm{a}$ \\
\hline Disturbed & $360(8) a$ & $176(7.1) \mathrm{a}$ & $5.2(0.83) \mathrm{a}$ & $16.6(0.60) \mathrm{a}$ & $1.0(0.06) \mathrm{a}$ & $2.2(0.37) \mathrm{a}$ \\
\hline $\begin{array}{l}\text { Undisturbed } \\
\text { AC } 756\end{array}$ & $300(20) b$ & $173(11.8) \mathrm{a}$ & $3.2(0.25) \mathrm{a}$ & $12.2(0.69) \mathrm{b}$ & $1.2(0.08) \mathrm{a}$ & $2.4(0.27) \mathrm{a}$ \\
\hline Disturbed & 330 (14) a & $114(2.2) \mathrm{a}$ & $3.0(0.47) \mathrm{a}$ & $12.8(0.60) \mathrm{a}$ & $0.8(0.03) \mathrm{a}$ & $2.0(0.16) \mathrm{a}$ \\
\hline $\begin{array}{l}\text { Undisturbed } \\
\text { RCAT Angora }\end{array}$ & $250(17) \mathrm{b}$ & $121(3.6) \mathrm{a}$ & $1.9(0.19) \mathrm{a}$ & $8.1(0.76) \mathrm{b}$ & $1.0(0.10) \mathrm{a}$ & $2.5(0.31) \mathrm{a}$ \\
\hline Disturbed & 340 (4) a & $139(3.3) \mathrm{a}$ & $3.9(0.78) \mathrm{a}$ & $14.0(0.26) \mathrm{a}$ & $0.8(0.04) \mathrm{a}$ & $2.0(0.20) \mathrm{a}$ \\
\hline Undisturbed & $270(17) \mathrm{b}$ & $132(2.1) \mathrm{a}$ & $3.4(0.77) \mathrm{a}$ & $10.0(1.12) \mathrm{b}$ & $1.1(0.13) \mathrm{a}$ & $3.0(0.61) \mathrm{a}$ \\
\hline
\end{tabular}

For each soybean line, means in a column followed by the same letter are not significantly different $(P<0.05)$. 

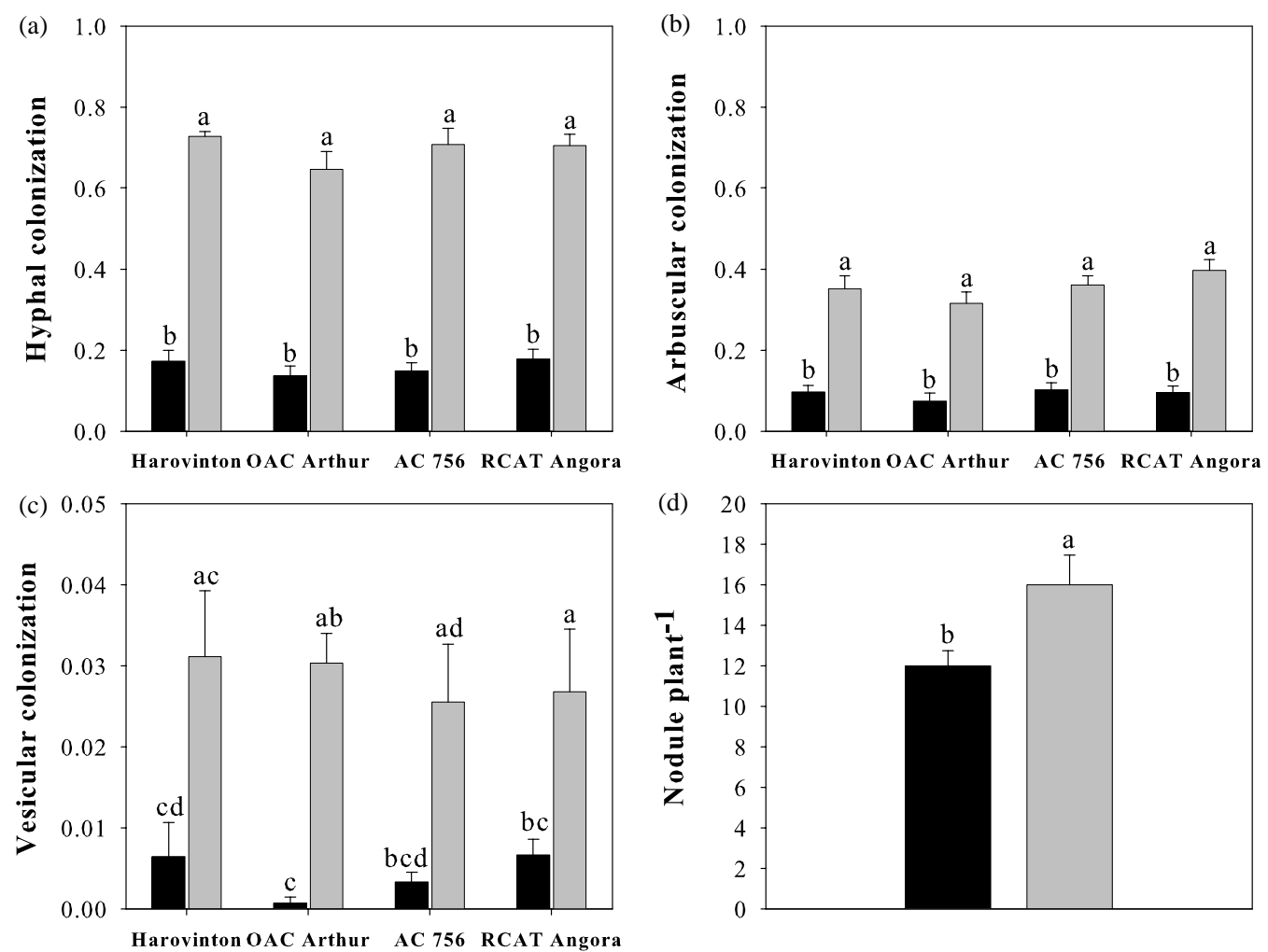

Fig. 1. Effect of soil disturbance (black bars disturbed and grey bars undisturbed) on (a) AMF hyphal colonization, (b) arbuscular colonization and (c) vesicular colonization of soybean roots of each line at $10 \mathrm{~d}$ after emergence. (d) Effect of soil disturbance on the nodulation of all four soybean lines combined. For each graph, bars with the same letter are not significantly different $(P<0.05)$. Error bars are SEM.

consistently smaller than in roots from disturbed soil (Fig. 4). Moreover, in plants inoculated with Bradyrhizobium and grown in undisturbed soil, the concentration of daidzein was $25 \%$ smaller than in those that were not inoculated (Fig. 5).

Concentrations of daidzein and coumestrol increased with mycorrhizal colonization but only up to amounts between 0.2 and 0.4 and after which they decreased. Genistein concentrations showed a steady decrease,

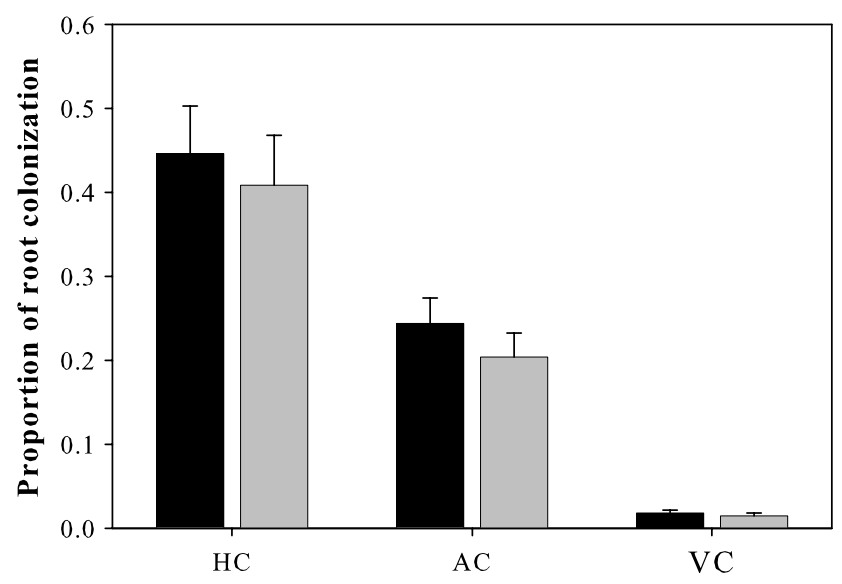

Fig. 2. Effect of B. japonicum inoculation (black bars inoculated and grey bars non-inoculated) on hyphal (HC), arbuscular (AC) and vesicular (VC) colonization of soybean roots $10 \mathrm{~d}$ after emergence. Error bars are SEM. independent of the amount of mycorrhizal or bradyrhizobial colonization (Fig. 6).

\section{Discussion}

The use of maize cycles with contrasting soil disturbance treatments as a tool to create AMF treatments to study the tripartite symbiosis formed by indigenous AMF, Bradyrhizobium and soybeans, was originally reported by Goss and

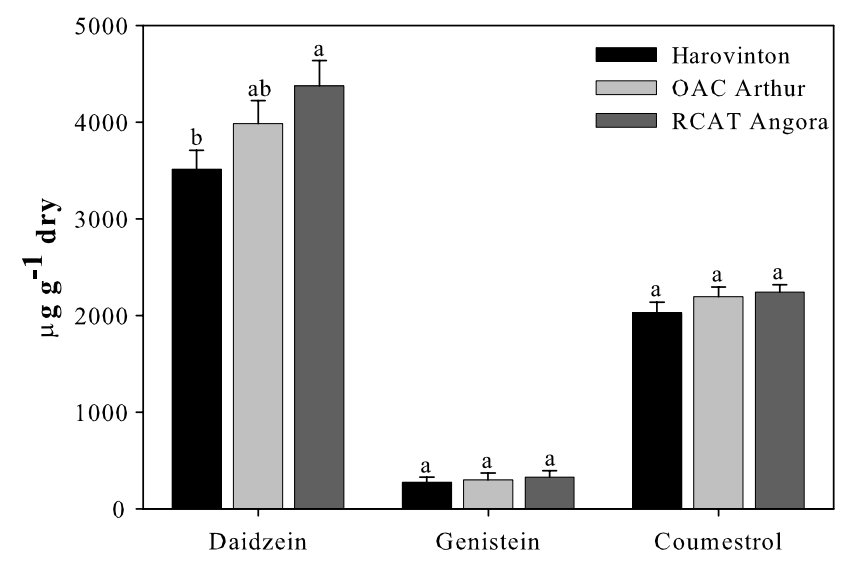

Fig. 3. Overall concentration of flavonoids in roots of three soybean lines 10 $\mathrm{d}$ after plant emergence. For each flavonoid, bars with the same letter are not significantly different $(P<0.05)$. Error bars are SEM. 


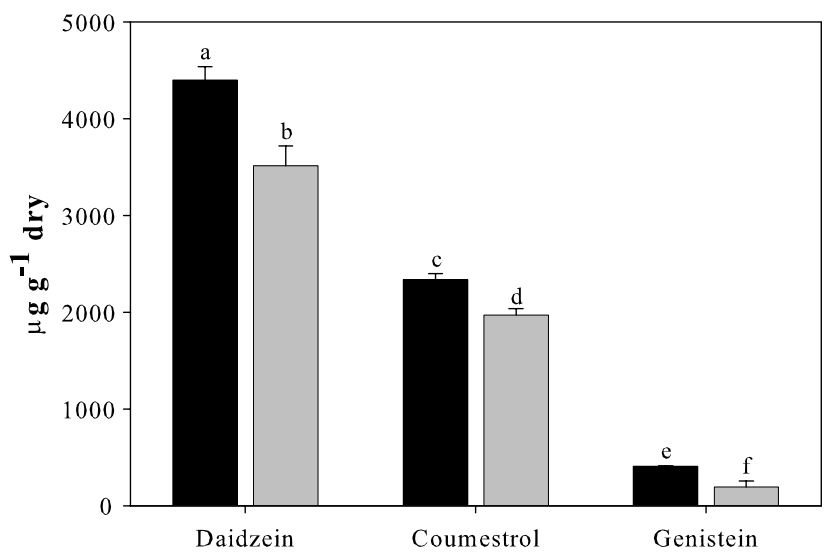

Fig. 4. Effect of soil disturbance (black bars disturbed and grey bars undisturbed) on the concentration of flavonoids in roots of soybean plants $10 \mathrm{~d}$ after emergence. Bars with the same letter are not significantly different $(P<0.05)$. Error bars are SEM.

de Varennes (2002), based on previous findings reported by Fairchild and Miller (1988). In this design, which enables the study of the tripartite symbiosis in virtually natural soil conditions, the differential in AMF colonization potentials provides the basis for identifying effects and processes. Interestingly, after the maize cycles, the soil concentration of $\mathrm{P}$ was greater in the undisturbed soil than that in the disturbed soil. Despite some conflicting reports, a greater development of extra-radical mycorrhizal mycelium appears to be associated with increased rates of solubilization and hydrolysis of insoluble and organic P, respectively (Smith and Read, 1997).

The larger colonization by indigenous AMF in soybean plants from undisturbed soil resulted in increased nodulation compared to plants with a smaller degree of AMF colonization grown in disturbed soil. The reverse was, however, not true. This finding contrasts, for example, with the works of Pacovsky et al. (1986); Xie et al. (1995) and supports the hypothesis that the infectivity of indigenous

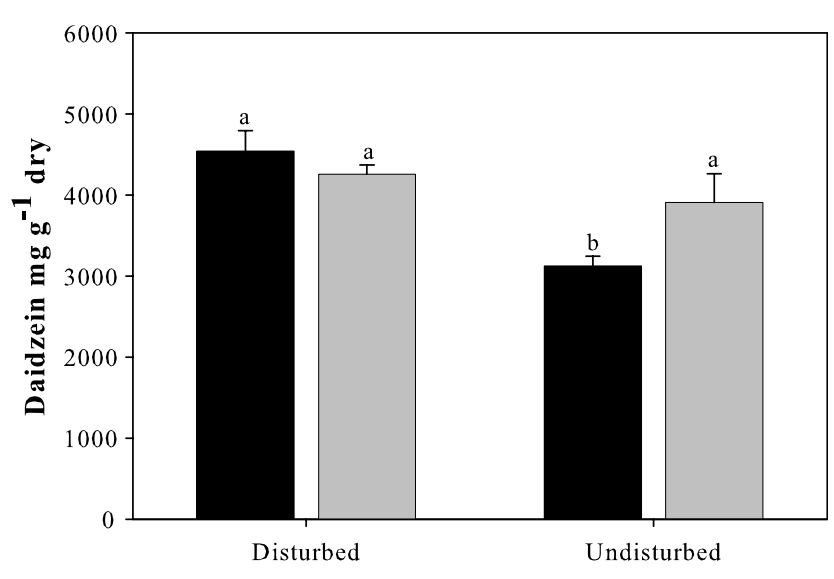

Fig. 5. The effect of soil disturbance and bradyrhizobial colonization (black bars inoculated and grey bars non-inoculated) on the daidzein content of 10 d-old soybean roots. Bars with the same letter are not significantly different as estimated by the Least Significant Difference (LSD) test $(P=0.05)$. Error bars are SEM.

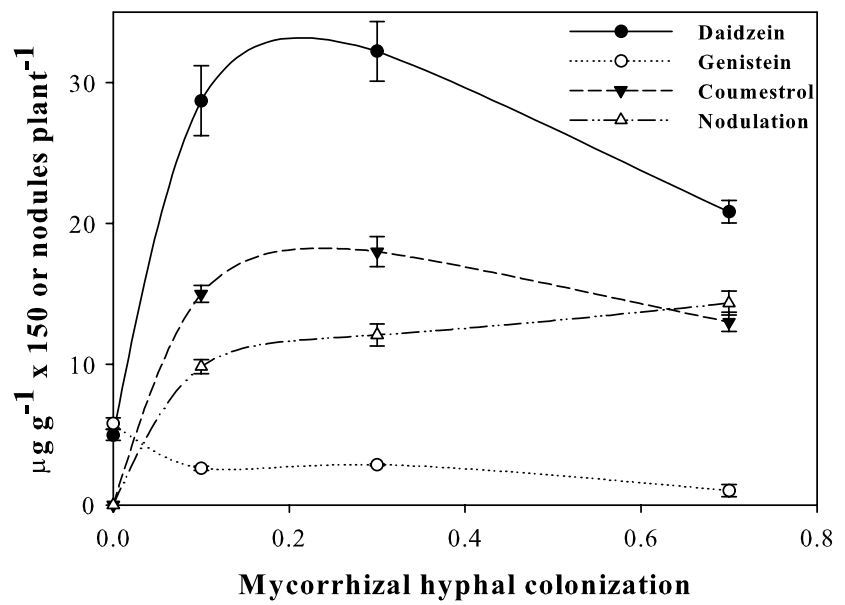

Fig. 6. Effect of colonization by AMF and Bradyrhizobium on the concentration of flavonoids in roots of three soybean lines. Zero in the $x$-axis corresponds to seed data. Data were ranked in categories of 0 to 0.2 , $0.2-0.4,0.4-0.6$ and $0.6-0.8$ mycorrhizal hyphal colonization. Data points up to 0.4 correspond to plants from disturbed soil, and all plants from undisturbed soil fell in the category between 0.6 and 0.8 . There were no plants with a proportion of AMF colonization between 0.4 and 0.6 in either soil disturbance treatment. The concentration of each flavonoid in roots between 0.6 and 0.8 colonization was significantly smaller than that of plants colonized up to 0.4 as estimated by the Tukey Honest Significant Difference test for unequal sample sizes (see Spjotvoll and Stoline, 1973) $(P<0.05)$. To reduce the coefficient of variation of nodulation, each plant was considered one experimental unit. Error bars are SEM.

AMF, which are well adapted to their environment, overcomes any additional benefits provided by the bacterial symbiont. Nevertheless, the possibility of a synergy involved in the tripartite symbiosis in which colonization by one microbe promotes colonization by the other is not excluded.

Mineralization and nitrification rates have been shown to be stimulated after soil disturbance operations (e.g., Kristensen et al., 2000), and that likely caused $\mathrm{NO}_{3}^{-}-\mathrm{N}$ to increase in the disturbed soil during the phase of maize cycles. Elevated soil $\mathrm{N}$ concentrations may inhibit the process of nodulation and $\mathrm{N}_{2}$ fixation, and the possibility of a $\mathrm{N}$ effect to explain the difference in nodulation between plants from undisturbed and disturbed soil needs to be considered. There are several reasons why this is unlikely to be an important factor in this experiment. Goss et al. (2002) had to add $63 \mathrm{~kg} \mathrm{~N}^{-1}$ to soil before biological $\mathrm{N}_{2}$ fixation was affected and this is much more than the concentration found in the disturbed pots. In the work of Goss and de Varennes (2002), and in the field experiment reported by P.M. Antunes (2004, Ph.D. thesis, University of Guelph, Canada), the same effects of soil disturbance on AMF colonization and nodulation were observed in $10 \mathrm{~d}$-old plants with similar $\mathrm{N}$ contents. The $\mathrm{N}$ content of each soybean seed used in the experiment was approximately $12.72 \pm 0.4 \mathrm{mg} \mathrm{N}$ seed $^{-1}$, which indicates that by $10 \mathrm{~d}$ after emergence, plants, particularly the ones from disturbed soil, had only just started to take up $\mathrm{N}$ from the soil. Although plants in disturbed soil were bigger, the shoot:root ratio of 
plants from disturbed and undisturbed soil was identical, suggesting that by $10 \mathrm{~d}$ there was no clear $\mathrm{N}$ deficiency. Generally shoot:root ratios decrease with decreasing N supply (Levin et al., 1989). Furthermore, it is quite possible that plants in undisturbed soil were smaller because they allocated more $\mathrm{C}$ and $\mathrm{N}$ to processes related to the establishment of microbial symbioses (e.g., the synthesis of signal compounds).

As in the study by Goss and de Varennes (2002) and in the field experiment reported by P.M. Antunes (2004, Ph.D. thesis, University of Guelph, Canada), nodulation was promoted by increased mycorrhizal colonization before any $\mathrm{P}$ had been taken up. The idea that the establishment of the tripartite symbiosis is not a function of increased $\mathrm{P}$ uptake is, therefore, re-affirmed.

Zinc is poorly mobile in soils and is often limiting to plant growth. However, AMF colonization can increase $\mathrm{Zn}$ uptake by roots at an early stage (Smith and Read, 1997), and overcome deficiency in different species (e.g., Thompson, 1990; Burkert and Robson, 1994). Zinc nutrition has also been associated with the negative effects of soil disturbance by tillage (Evans and Miller, 1988; Fairchild and Miller, 1988). Yadav et al. (1986) demonstrated that $P$ and $\mathrm{Zn}$ interacted significantly, and applications at different concentrations consistently increased the number of nodules, nodule weight, leghaemoglobin content and $\mathrm{N}_{2}$ fixation. Zinc was not absorbed by soybeans up to $10 \mathrm{~d}$ after emergence and it is, therefore, unlikely that the early symbiotic interaction was a function of this or any other soil micronutrient. This result clearly supports the first hypothesis. It extends the knowledge about the factors associated with the establishment of the tripartite symbiosis and represents another indication that the key to understanding this biological process is likely in chemical signalling and not direct nutrient effects.

The root daidzein content appears to reflect the seed content only for RCAT Angora. Trebovac Stojkov (2004, M.Sc. thesis, University of Guelph, Canada) reported similar concentrations of daidzein and genistein in the roots of 4-week-old soybeans of the same lines used in the present study. Glycitein was not detected in either study. Although RCAT Angora presented increased daidzein concentrations in the root, neither AMF nor Bradyrhizobium showed any preference for a particular line, which does not support the second hypothesis. It seems that the tripartite symbiosis is more susceptible to soil management practices and their potential to affect the symbionts than to the variations associated with genetic differences in the soybean lines. Although the development of soybean lines with increased capabilities to synthesize specific flavonoids may be of interest, the results indicated that external applications of these compounds appear to be more promising in the context of the tripartite symbiosis. The work by Zhang and Smith (1995), in which the addition of genistein increased soybean nodulation and resulted in an earlier onset of $\mathrm{N}_{2^{-}}$ fixation, is an example of the potential use that biochemical signals may have. Nevertheless, more work is needed on this subject, as plant genotypes with greater capacity to exude specific flavonoids have been found to positively affect nodulation (Hungria and Phillips, 1993; Hernandez et al., 1995).

The concentration of daidzein was at least four times greater in the root than in the seed. Coumestrol, which was absent in the seed, was synthesized to give notable values in the root. Conversely, the concentration of genistein in the root was less than that in the seed, while glycitein and formononetin were never detected. Of the commercial flavonoids used by Xie et al. (1995) to study their effect on mycorrhizal colonization in soybean, genistein was the only one that did not produce a significant stimulatory outcome, whereas daidzein had the greatest effect on the percentage of root length colonized by Glomus mosseae compared to a control which had no flavonoids applied. Mycorrhizal fungi may have evolved to use the most abundant flavonoid to induce hyphal branching and stimulate colonization. Other studies either failed to identify an effect of genistein on hyphal growth (Baptista and Siqueira, 1994) and root colonization (Siqueira et al., 1991) or have even indicated an inhibition of the fungal development (Chabot et al., 1992).

Coumestrol has been shown to be stimulatory to hyphal growth and root colonization (Morandi et al., 1992; Xie et al., 1995). AMF may also have adapted to recognizing this signal compound which was accumulated in the second greatest amount. Larose et al. (2002) reported that alfalfa plants perceived AMF-derived fungal signals and accumulated daidzein and coumestrol, whereas the concentration of formononetin was reduced and that of genistein was not affected. The concentration of flavonoids found in legumes is influenced by genotype and environment (Hoeck et al., 2000). Larose et al. (2002) detected concentrations of daidzein, genistein and coumestrol in alfalfa in the order of 200-300, 10-60 and 10-20 $\mathrm{\mu g} \mathrm{g}^{-1}$, respectively, which is at least one to two orders of magnitude smaller than the values presented here. Such discrepancy may not solely be explained by the fact that the plant species are different but also because their measurements were made in older plants, which were grown for $20 \mathrm{~d}$ in sterile medium before being inoculated with AMF. However, Cho and Harper (1991) also reported significantly smaller root concentrations of daidzein and coumestrol in $9 \mathrm{~d}$-old plants of four soybean lines. If comparisons are to be done between studies, they should account for the HPLC method. Trebovac Stojkov (2004, M.Sc. thesis, University of Guelph, Canada) used the same HPLC method but detected significant variations depending on the drying process used. The discrepancy in root concentration of flavonoids between this study and, for example, the studies of Cho and Harper (1991) or Larose et al. (2002) can only be explained at this point by a combination of both factors, different plant genotypes and handling of the samples. At $10 \mathrm{~d}$ after plant emergence the concentrations of daidzein, coumestrol and genistein were 
greater in roots under disturbed soil, for which both AMF and bradyrhizobial symbioses were not as developed as in plants from undisturbed soil. This result suggests that the tripartite symbiosis is initiated prior to $10 \mathrm{~d}$ after emergence, and the activity of these compounds is changed mostly in the early stages of colonization by both fungal and bacterial symbionts. The synthesis, accumulation and most likely exudation by the roots of specific flavonoids seem, therefore, to be dependant on the time course of development of the tripartite symbiosis (see Fig. 6).

The significant increase in daidzein and coumestrol appears to result mainly from the development of mycorrhizal colonization; consistent with the findings of Larose et al. (2002). However, such an hypothesis needs further investigation because the root concentration of these flavonoids between plants solely colonized by AMF under disturbed and undisturbed soil was identical. Moreover, the values reported by Trebovac Stojkov (2004, M.Sc. thesis, University of Guelph, Canada) were for soybean plants grown in sterilized vermiculite. Nevertheless, since daidzein and coumestrol have also been shown to be involved in the bradyrhizobial symbiosis (e.g., Kosslak et al., 1987; Peters and Verma, 1990; Cho and Harper, 1991; Schmidt et al., 1994; Rao and Cooper, 1995), they are likely to play a key role in the early stages of the tripartite symbiosis. It can be argued that the concentrations of daidzein, coumestrol and genistein were smaller in roots under undisturbed soil, for which both AMF and bradyrhizobial symbioses were more developed than in plants from disturbed soil, not just because of their synthesis being a function of the time course of development of both symbionts but due to a greater exudation into the rhizosphere. If this is the case then genistein may play a major role in the tripartite symbiosis, particularly in the nodulation process. The concentration of genistein was approximately three times smaller in the root than the original concentration in the seed. Graham et al. (1990), for example, reported that the isoflavone conjugates of daidzein and genistein were hydrolysed to release those compounds following infection with the pathogen Phytophthora. Their results were, however, inconclusive in relation to a new synthesis of those isoflavones.

\subsection{Conclusions}

This work provides the first data linking the function of different flavonoids to the establishment of the tripartite symbiosis of soybeans, indigenous AMF and Bradyrhizobium. It is also the first to use the effect of soil disturbance to investigate changes in the plant content of specific flavonoids involved in the tripartite symbiosis of indigenous AMF, Bradyrhizobium and soybean. Soil disturbance treatments enabled the study of the tripartite symbiosis in soil with indigenous populations of microorganisms, which is a step forward from studies in which sterile substrates are used. The results suggest that daidzein, genistein and coumestrol are important signal molecules associated with the tripartite symbiosis and that the accumulation of these signal molecules in the plant varies according to the development of the symbioses. However, differences in flavonoid accumulation by roots might also be due to effects of soil disturbance other than the change of potential for AMF colonization. Furthermore, this study can be seen as providing a 'snapshot' at $10 \mathrm{~d}$ after emergence, and the idea that flavonoids are produced and released by the roots as a function of the development of both microbial symbiosis is currently being further evaluated. In summary, results of this research indicated that:

- The interaction leading to the establishment of the tripartite symbiosis was initiated prior to $10 \mathrm{~d}$ after emergence;

- The root colonization by AMF had a positive effect on nodulation but the reverse did not occur;

- Uptake of P and Zn from soil was not important for the development of the interaction;

- The use of soybean lines with the different seed concentrations of isoflavones used here does not appear to influence the establishment of the tripartite symbiosis;

- Certain flavonoids (e.g., glycitein, formononetin) do not seem to act as signal molecules in the establishment of the tripartite symbiosis;

- The significant increase in daidzein and coumestrol in the root appears to result mainly from the development of mycorrhizal colonization, and that accumulation is reduced for greater amounts of root colonization by both microbial symbionts;

- The concentration of genistein is approximately three times smaller in the root than in the seed and that reduction is more evident when both symbionts are well established;

- Daidzein, genistein and coumestrol likely play key roles in the early stages of the interaction.

\section{Acknowledgements}

Pedro M. Antunes was funded by the Foundation for Science and Technology of Portugal. We are thankful to Julia Zilka and Miranda Labbe for their invaluable technical support.

\section{References}

Antunes, P.M., Goss, M.J., in press, Communication in the tripartite symbiosis formed by arbuscular mycorrhizal fungi, rhizobia and legume plants: a review. In: Zobel, R.W., Wright, S.F. (Eds.), Roots and Soil Management: Interactions between Roots and the Soil, Agronomy Monograph no. 48., American Society of Agronomy, Madison, WI, pp. 199-222. 
Baptista, M.J., Siqueira, J.O., 1994. Efeito de flavonoides na germinação de esporos e no crescimento assimbiótico do fungo micorrízico arbuscular Gigaspora gigantea. Revista Brasileira de Fisiologia Vegetal 6, 127-134.

Barea, J.M., Azcon-Aguilar, R., Azcon-Aguilar, C., 1992. Vesiculararbuscular mycorrhizal fungi in nitrogen-fixing systems. In: Norris, J.R., Read, D.J., Varma, A.K. (Eds.), Methods in Microbiology: Techniques for the Study of Mycorrhizae. Academic Press, San Diego, pp. 391-416.

Bécard, G., Taylor, L.P., Douds, D.D., Pfeffer, P.E., Doner, L.W., 1995. Flavonoids are not necessary plant signal compounds in arbuscular mycorrhizal symbiosis. Molecular Plant-Microbe Interactions 8, 252258.

Brundrett, M.C., Piché, Y., Peterson, R.L., 1984. A new method for observing the morphology of vesicular-arbuscular mycorrhizae. Canadian Journal of Botany 62, 2128-2134.

Burkert, B., Robson, A.D., 1994. ${ }^{65} \mathrm{Zn}$ uptake in subterranean clover (Trifolium subterraneum L.) by three vesicular-arbuscular mycorrhizal fungi in a root-free sandy soil. Soil Biology \& Biochemistry 26, 1117 1124.

Chabot, S., Bel-Rhlid, R., Chênevert, R., Piché, Y., 1992. Hyphal growth promotion in vitro of the VA mycorrhizal fungus. Gigaspora margarita Becker and Hall by the activity of structurally specific flavonoid compounds under $\mathrm{CO}_{2}$ enrichment conditions. New Phytologist 122, $461-467$.

Cho, M.J., Harper, J.E., 1991. Effect of inoculation and nitrogen on isoflavonoid concentration in wild-type and nodulation-mutant soybean roots. Plant Physiology 95, 435-442.

Cluett, H.C., Boucher, D.H., 1983. Indirect mutualism in the legumeRhizobium-mycorrhizal fungus interaction. Oecologia 59, 405-408.

Conover, W.J., Johnson, M.E., Johnson, M.M., 1981. A comparative study of tests of homogeneity of variances, with applications to the outer continental shelf bidding data. Technometrics 23, 351-361.

El-Hassanin, A.S., Lynd, J.Q., 1985. Soil fertility effects with tripartite symbiosis for growth, nodulation and nitrogenase activity of Vicia faba L. Journal of Plant Nutrition 8, 491-504.

Evans, D.G., Miller, M.H., 1988. Vesicular-arbuscular mycorrhizas and the soil-disturbance-induced reduction of nutrient absorption in maize. I. Casual relations.. New Phytologist 110, 67-74.

Fairchild, G.L., Miller, M.H., 1988. Vesicular-arbuscular mycorrhizas and the soil-disturbance-induced reduction of nutrient absorption in maize. II. Development of the effect. New Phytologist 110, 75-84.

Fisher, R.F., Long, S.R., 1993. Interactions of NodD at the nod box: NodD binds to two distinct sites on the same face of the helix and induces a bend in DNA. Journal of Molecular Biology 233, 336-348.

Franke, A.A., Custer, L.J., Cerna, C.M., Narala, K., 1995. HPLC analysis of dietary phytoestrogens from legumes and from human urine. Proceedings of the Society for Experimental Biology and Medicine 203, 16-26.

George, E., Marschner, H., Jakobsen, I., 1995. Role of arbuscular mycorrhizal fungi in uptake of phosphorus and nitrogen from soil. Critical Reviews in Biotechnology 15, 257-270.

Goss, M.J., de Varennes, A., 2002. Soil disturbance reduces the efficacy of mycorrhizal associations for early soybean growth and $\mathrm{N}_{2}$ fixation. Soil Biology \& Biochemistry 34, 1167-1173.

Goss, M.J., de Varennes, A., Smith, P.S., Ferguson, J.A., 2002. N ${ }_{2}$ fixation by soybeans grown with different levels of mineral nitrogen, and the fertilizer replacement value for a following crop. Canadian Journal of Soil Science 82, 139-145.

Graham, T.L., Kim, J.E., Graham, M.Y., 1990. Role of constitutive isoflavone conjugates in the accumulation of glyceollin in soybean infected with Phytophthora megasperma. Molecular Plant-Microbe Interactions 3, 157-166.

Harrison, M.J., Dixon, R.A., 1993. Isoflavonoid accumulation and expression of defence gene transcripts during the establishment of vesicular-arbuscular mycorrhizal associations in roots of Medicago truncatula. Molecular Plant-Microbe Interactions 6, 643-654.
Hernandez, G., Ramirez, M., Suarez, R., Fuentes, S.I., 1995. Root exuded nod-gene inducing signals limit the nodulation capacity of different alfalfa varieties with Rhizobium meliloti. Plant Cell 14, 626-629.

Hoeck, J.A., Fehr, W.R., Murphy, P.A., Welke, G.A., 2000. Influence of genotype and environment on isoflavone contents of soybean. Crop Science 40, 48-51.

Hungria, M., Phillips, D.A., 1993. Effects of a seed color mutation on rhizobial nod-gene-inducing flavonoids and nodulation in common bean. Molecular Plant-Microbe Interactions 6, 418-422.

Keeney, D.R., Nelson, D.W., 1982. Nitrogen-inorganic forms. In: Page, A.L., Miller, R.H., Keeney, D.R. (Eds.), Methods of Soil Analysis, second ed. Soil Science Society of America, Madison, WI, pp. 643-698.

Knudsen, D., Peterson, G.A., Pratt, P.F., 1982. Lithium, sodium and potassium. In: Page, A.L., Miller, R.H., Keeney, D.R. (Eds.), Methods of Soil Analysis, second ed. Soil Science Society of America, Madison, WI, pp. 225-246.

Kosslak, R.M., Bookland, R., Barkei, J., Paaren, E.H., Appelbaum, E.R., 1987. Induction of Bradyrhizobium japonicum common nod genes by isoflavones isolated from Glycine max. Proceedings of the National Academy of Sciences 84, 7428-7432.

Kristensen, H.L., McCarty, G.W., Meisinger, J.J., 2000. Effects of soil structure disturbance on mineralization of organic soil nitrogen. Soil Science Society of America Journal 64, 371-378.

Kruskal, W.H., Wallis, W.A., 1952. Use of ranks in one-criterion variance analysis. Journal of the American Statistics Association 47, 583-621.

Larose, G., Chênevert, R., Moutoglis, P., Gagné, S., Piché, Y., Vierheilig, H., 2002. Flavonoid levels in roots of Medicago sativa are modulated by the developmental stage of the symbiosis and the root colonizing arbuscular mycorrhizal fungus. Journal of Plant Physiology 159, 1329-1339.

Levin, S.A., Mooney, H.A., Field, C., 1989. The dependence of plant root: shoot ratios on internal nitrogen concentration. Annals of Botany (London) 64, 71-75.

Mathesius, U., Schlaman, H.R.M., Spaink, H.P., Sautter, C., Rolf, B.G., Djordjevic, M.A., 1998. Auxin transport inhibition precedes root nodule formation in white clover roots and is regulated by flavonoids and derivatives of chitin oligosaccharides. Plant Journal $14,23-24$.

McGonigle, T.P., Miller, M.H., Evans, D.G., Fairchild, G.L., Swan, J.A., 1990. A new method which gives an objective measure of colonization of roots by vesicular-arbuscular mycorrhizal fungi. New Phytologist 115, 495-501.

Morandi, D., Bailey, J.A., Gianinazzi-Pearson, V., 1984. Isoflavonoid accumulation in soybean roots infected with vesicular-arbuscular mycorrhizal fungus. Physiology and Plant Pathology 24, 357-364.

Morandi, D., Branzanti, B., Gianinazzi-Pearson, V., 1992. Effect of some plant flavonoids on in vitro behaviour of an arbuscular mycorrhizal fungus. Agronomie 12, 811-816.

Olsen, S.R., Summers, L.E., 1982. Phosphorus. In: Page, A.L., Miller, R.H., Keeney, D.R. (Eds.), Methods of Soil Analysis, second ed. Soil Science Society of America, Madison, WI, pp. 403-430.

Pacovsky, R.S., Paul, E.A., Bethlenfalvay, G.J., 1986. Response of mycorrhizal and P-fertilized soybeans to nodulation by Bradyrhizobium or ammonium nitrate. Crop Science 26, 145-150.

Peters, N.K., Verma, D.P.S., 1990. Phenolic compounds as regulators of gene expression in plant-microbe interactions. Molecular PlantMicrobe Interactions 3, 4-8.

Rao, J.R., Cooper, J.E., 1995. Soybean nodulation rhizobia modify nod gene inducers daidzein and genistein to yield aromatic products that can influence gene-inducing acting activity. Molecular Plant-Microbe Interactions 8, 855-862.

Richards, J.E., 1993. Chemical characterization of plant tissue. In: Carter, M.R. (Ed.), Soil Sampling Methods of Analysis. Canadian Society of Soil Science, Lewis Publishers, Danvers, MA, pp. 115139. 
Schmidt, P.E., Broughton, W.J., Werner, D., 1994. Nod factors of Bradyrhizobium japonicum and Rhizobium sp. NG234 induce flavonoid accumulation in soybean root exudates. Molecular Plant-Microbe Interactions 7, 384-390.

Shapiro, S.S., Wilk, M.B., Chen, H.J., 1968. A comparative study of various tests of normality. Journal of the American Statistics Association 63, 1343-1372.

Siqueira, J.O., Safir, G.R., Nair, M.G., 1991. Stimulation of vesiculararbuscular mycorrhiza formation and growth of white clover by flavonoid compounds. New Phytologist 118, 87-93.

Smith, S.E., Read, D.J., 1997. Mycorrhizal Symbioses, second ed. Academic Press, London, UK.

Spjotvoll, E., Stoline, M.R., 1973. An extension of the T-method of multiple comparison to include the cases with unequal sample sizes. Journal of the American Statistics. Association 68, 976-978.

Thomas, R.L., Sheard, R.W., Moyer, J.R., 1967. Comparison of conventional and automated procedures for $\mathrm{N}, \mathrm{P}$ and $\mathrm{K}$ analysis of plant material using a single digestion. Agronomy Journal 59, 240-243.

Thompson, J.P., 1990. Soil sterilization methods to show VA-mycorrhizae aid $\mathrm{P}$ and $\mathrm{Zn}$ nutrition of wheat in vertisols. Soil Biology \& Biochemistry 22, 229-240.
Tukey, J.W., 1949. Comparing individual means in the analysis of variance. Biometrics 5, 99-114.

Vejsadová, H., Siblíková, D., Gryndler, M., Simon, T., Miksik, I., 1993. Influence of inoculation with Bradyrhizobium japonicum and Glomus claroideum on seed yield of soybean under greenhouse and field conditions. Journal of Plant Nutrition 16, 619-629.

Vierheilig, H., Bago, B., Albrecht, C., Poulin, M.-J., Piché, Y., 1998. Flavonoids and arbuscular-mycorrhizal fungi. In: Buslig, B., Manthley, J. (Eds.), Flavonoids in the Living System. Plenum Press, New York, pp. 9-32.

Xie, Z.-P., Staehelin, C., Vierheilig, H., Wiemken, A., Jabbouri, S., Broughton, W.J., Vögeli-Lange, R., Boller, T., 1995. Rhizobial nodulation factors stimulate mycorrhizal colonization of nodulating and nonnodulating soybeans. Plant Physiology 108, 1519-1525.

Yadav, D.S., Antil, R.S., Singh, M., Kumar, V., 1986. Effect of P and Zn on number of nodules, nodule weight, leghaemoglobin content, N utilization and fixation in cowpea (Vigna unguiculata L. Walp.). Agrochimica 30, 252-260.

Zhang, F., Smith, D.L., 1995. Preincubation of Bradyrhizobium japonicum with genistein accelerates nodule development of soybean (Glycine max. (L.) Merr.) at suboptimal root zone temperatures. Plant Physiology 108, 961-968. 